\title{
Mobilidade urbana e transportes não-motorizados: um estudo de caso do uso da bicicleta na cidade de Januária/MG
}

Urban mobility and non-motorized transport: a case study of bicycle use in the city of Januária / MG

\author{
NASCIMENTO, Jussara Cruz. Especialista/Graduação em Engenharia Civil \\ Instituto Federal de Educação, Ciência e Tecnologia do Norte de Minas Gerais - Campus Januária. Fazenda São \\ Geraldo, S/N Km 06 - Januária - Minas Gerais - Brasil. CEP: 39.480-000 / Telefone: (38) 3629.4600 / E-mail: \\ jussara.nascimento@ifnmg.edu.br
}

PRATES, Admilson Eustáquio. Doutor/Graduação em Filosofia

Instituto Federal de Educação, Ciência e Tecnologia do Norte de Minas Gerais - Campus Salinas. Rodovia MG404, S/N Km 02- Salinas - Minas Gerais - Brasil. CEP: 39.560-000 / Telefone: (38) 3841.7000 / E-mail:

admilson.prates@ifnmg.edu.br

DOURADO, Lara Fernanda Nunes. Especialista/Graduação em Engenharia Civil Instituto Federal de Educação, Ciência e Tecnologia do Norte de Minas Gerais - Campus Januária. Fazenda São Geraldo, S/N Km 06 - Januária - Minas Gerais - Brasil. CEP: 39.480-000 / Telefone: (38) 3629.4600 / E-mail: lara.dourado@ifnmg.edu.br

\section{RESUMO}

O presente artigo tem por objetivo apresentar a análise realizada sobre as políticas públicas elaboradas pelo poder público municipal de Januária/MG, de forma a verificar se elas, devidamente, atendem às demandas de viagens por bicicletas; garantindo mobilidade, acessibilidade e segurança para os ciclistas. 0 método de pesquisa utilizado foi pesquisa exploratória, seguido de revisão bibliográfica, que foi feita através de análise documental para identificação das políticas públicas para o uso de bicicletas como modal de transporte e sua aplicação na cidade. 0 resultado da pesquisa foi que existe uma tensão entre a legislação e a materialização da lei. Dessa maneira, podemos concluir que é necessário que as políticas públicas sejam devidamente implementadas, de maneira a atender o uso de bicicletas, garantindo mobilidade, acessibilidade e segurança para os ciclistas, tornando a cidade plenamente acessível a todos os seus cidadãos.

Palavras-chave: Bicicleta, Mobilidade Urbana, Políticas Públicas, Transporte não-motorizado.

\section{ABSTRACT}

The present article has as aim to present the analyze carried out on the public policies developed by the municipal government of Januária/MG, in order to verify whether they, properly, meet the demands of bicycle travel; ensuring mobility, accessibility and safety for cyclists. The research method used was exploratory research, followed by a bibliographic review, which was done through documentary analysis to identification of the public policies for the use of bicycles as a mode of transport and its application in the city. The result of the research was that there is a tension between the legislation and the materialization of the law. That way, we can conclude that it is necessary that public policies are properly implemented, in order to meet the use of bicycles, ensuring mobility, accessibility and safety for cyclists, making the city fully accessible to all its citizens.

keywords: Bicycles, Urban Mobility, Public Policies, Non-motorized transport. 
NASCIMENTO, J. C.; PRATES, A. E.; DOURADO, L. F. N.

Mobilidade urbana e transportes não-motorizados: um estudo de caso do uso da bicicleta na cidade de Januária/MG

\section{Introdução}

No Brasil, assim como em outros países em desenvolvimento, tem-se o predomínio do uso intensivo do automóvel para deslocamentos no espaço urbano e regional. Como consequência, nota-se um cenário de congestionamentos, de privatização do espaço público, de desorganização do espaço urbano e de impactos ambientais. Vencer essas barreiras, para atender às demandas sociais e ambientais, torna-se um desafio para o poder público e a sociedade nas cidades brasileiras.

$\mathrm{Na}$ medida em que as cidades se desenvolvem, o emprego de infraestrutura direcionada à circulação de ciclistas e ao incentivo do uso da bicicleta como meio de transporte desempenham importante papel para o desenvolvimento sustentável e para melhoria do trânsito. De modo que proporcionam uma cidade ambientalmente mais agradável e menos nociva à saúde humana, favorecendo, portanto, um espaço urbano mais organizado, equânime, humanizado, saudável e acessível a todos.

Para tornar a utilização desse modal uma prática corrente, é preciso enfrentar as dificuldades estruturais e buscar mudanças de paradigmas. É possível promover mudanças desde que haja vontade política, planejamento, distribuição igualitária dos espaços de circulação e educação para o trânsito (SILVA, 2017).

O município de Januária, situado no Norte de Minas Gerais, apesar do aumento considerável da frota de veículos automotores, o uso de modais nãomotorizados, especialmente bicicletas, ainda é muito comum, sobretudo pelos que se deslocam para o trabalho e escola. Dentre outras questões, tal uso se dá como forma de economicidade nos deslocamentos. A cidade oferece um pequeno trecho cicloviário, contudo não há infraestrutura eficiente e suficiente que atenda tal demanda, deixando esse público vulnerável aos riscos inerentes a quem trafega no trânsito da cidade. Isto leva ao questionamento de como construir uma política de planejamento e de gestão urbana que pauta pelas necessidades dos ciclistas e, com isso, uma política de sustentabilidade e melhoria do trânsito?

De tal modo, este artigo tem por objetivo apresentar a análise realizada sobre as políticas públicas elaboradas pelo poder público municipal de Januária/MG, de forma a verificar se elas atendem devidamente à demanda de viagens por bicicletas, garantindo mobilidade, acessibilidade e segurança para os ciclistas. 


\section{O uso da bicicleta e a política nacional de mobilidade urbana}

As cidades brasileiras, em sua grande maioria, se desenvolveram de forma desarmônica, sendo nítidas as desigualdades sociais representadas pelos arranjos desordenados de habitações e aglomerações urbanas. Os vários espaços tornam-se inadequados para comportar, de maneira satisfatória, a acentuada demanda de veículos motorizados e modos não-motorizados, resultando no surgimento de sérios problemas na prestação dos serviços públicos básicos, e, por conseguinte, na mobilidade das pessoas pela cidade.

O reconhecimento dessa realidade tem desafiado os governos a criarem medidas e ações que diminuam esse impacto na qualidade de vida das populações, de forma a criarem espaços urbanos mais igualitários, que favoreçam as parcelas populacionais menos favorecidas.

Nessa perspectiva, as políticas públicas de mobilidade urbana sustentável visam solucionar os problemas de transportes, levando em conta os aspectos sociais, econômicos e ambientais da sociedade envolvida. Porém, tal abordagem torna-se muito complexa, devido aos sérios desafios enfrentados na implementação de políticas públicas de mobilidade urbana, uma vez que para trazer contribuição efetiva, precisa ter o envolvimento de toda a sociedade, além de boa vontade política na elaboração de medidas que tragam resultados positivos para os problemas de mobilidade urbana (SIQUEIRA; LIMA, 2015).

A preocupação em buscar soluções para os problemas ocasionados pelo desenvolvimento desordenado e as condições de deslocamento das cidades começou a ganhar força nas discussões políticas somente no início deste século; em 2001, quando foi aprovada a Lei 10.257, intitulada Estatuto da Cidade, que regulamentou os art. 182 e 183 da Constituição Federal de 1988. Segundo pontua Brasil, no Caderno de Referência $n^{\circ} 1$ da Coleção Bicicleta Brasil, esse instrumento legal "garante o direito às cidades sustentáveis, entendido como direito à terra urbana, à moradia, ao saneamento ambiental, à infraestrutura urbana, ao transporte e aos serviços públicos, ao trabalho e ao lazer, para as presentes e futuras gerações” (2007, p. 13).

Em 2003, para efetivar os objetivos propostos no Estatuto, o Governo 
NASCIMENTO, J. C.; PRATES, A. E.; DOURADO, L. F. N.

Mobilidade urbana e transportes não-motorizados: um estudo de caso do uso da bicicleta na cidade de Januária/MG

Federal instituiu o Ministério das Cidades. Neste mesmo ano, realizou a $1^{\text {a }}$ Conferência Nacional das Cidades, em que foi criado o Conselho Nacional das Cidades (ConCidades) e traçado os princípios e diretrizes para a formulação do Plano Nacional de Desenvolvimento Urbano - PNDU. Dessa forma, os poderes públicos passaram a buscar soluções e ações para a melhoria da mobilidade e desenvolvimento urbano, de forma a tornar as cidades mais democráticas e sustentáveis.

A formulação da política para construção de cidades sustentáveis veio promover a participação do Governo Federal, com proposições de planejamento integrado nas questões de mobilidade urbana. Essa política tem foco na intersecção de quatro campos de ação: desenvolvimento urbano, sustentabilidade ambiental, inclusão social e democratização do espaço. Esse último inclui o acesso democrático à cidade e a valorização dos deslocamentos de ciclistas (BRASIL, 2007, p. 13).

Para a valorização da utilização da bicicleta, o Governo Federal cria o Programa Nacional de Mobilidade por Bicicleta - Bicicleta Brasil - instituído pela Portaria $n^{\circ}$ 399, de 22 de setembro de 2004 (BRASIL, 2007). Posteriormente, foi estabelecida a obrigatoriedade da elaboração do Plano de Transporte Urbano Integrado às cidades com mais de 500 mil habitantes, o qual deve ser compatível com o Plano Diretor da cidade. No entanto, a Resolução $n^{\circ} 34$, de 01 de julho de 2005, do Conselho das Cidades, adota outra denominação para o Plano de Transporte Urbano Integrado, nomeando-o de Plano Diretor de Transporte e da Mobilidade - PlanMob - que deve garantir a diversidade das modalidades de transporte; priorizando o transporte coletivo e os modos não motorizados e valorizando o pedestre, além disso, deve garantir o controle da expansão urbana, a universalização do acesso à cidade, a melhoria da qualidade ambiental e o controle dos impactos no sistema de mobilidade gerados pela ordenação do uso do solo (BRASIL, 2005).

A intenção não foi só mudar o nome, mas reformular o seu conceito. A mobilidade urbana passa a ser um atributo das cidades, relativo ao deslocamento de pessoas e bens no espaço urbano, utilizando, para isto, veículos, vias e toda a infraestrutura urbana; devendo promover a inclusão social, a sustentabilidade ambiental, a gestão participativa e a democratização do espaço público. Também ouve mudança na obrigatoriedade de elaboração, a partir de então, o Ministério das Cidades, por meio da Secretaria Nacional de Transporte e da Mobilidade Urbana 
NASCIMENTO, J. C.; PRATES, A. E.; DOURADO, L. F. N.

Mobilidade urbana e transportes não-motorizados: um estudo de caso do uso da bicicleta na cidade de Januária/MG

- SeMob -, decidiu sua elaboração por todas as cidades com mais de 100 mil habitantes, levando em conta que nestas ainda é possível reorientar os modelos de urbanização e de circulação de maneira preventiva (XAVIER, 2007).

Por conseguinte, em janeiro 2012, foi sancionada Lei $n^{0} 12.587 / 2012$, que têm como objetivos melhorar a acessibilidade e a mobilidade das pessoas e cargas nos municípios e integrar os diferentes modos de transporte. A legislação que institui as diretrizes da Política Nacional de Mobilidade Urbana dá prioridade aos meios de transporte não motorizados e ao serviço público coletivo, além da integração entre os modos e serviços de transporte urbano (XAVIER, 2007).

A Política Nacional de Mobilidade Urbana passou a exigir que os municípios com população acima de 20 mil habitantes, além de outros, elaborem e apresentem plano de mobilidade urbana, com a intenção de planejar o crescimento das cidades de forma ordenada. Inicialmente, o prazo para os municípios elaborarem os planos eram de três anos, a partir da data de vigência da Lei, sob pena de as prefeituras perderem acesso a recursos federais para investimentos em mobilidade urbana.

No ano de 2018, foi publicada uma medida provisória alterando esse prazo para sete anos. Segundo BRASIL (2012), capítulo V, das diretrizes para o planejamento e gestão dos sistemas de mobilidade urbana

\footnotetext{
O Plano de Mobilidade Urbana é o instrumento de efetivação da Política Nacional de Mobilidade Urbana e deverá contemplar os princípios, os objetivos e as diretrizes desta Lei, bem como: (...)§ $3^{\circ} 0$ Plano de Mobilidade Urbana será compatibilizado com o plano diretor municipal, existente ou em elaboração, no prazo máximo de sete anos, contado da data de entrada em vigor desta Lei. $\S 4^{\circ}$ Os Municípios que não tenham elaborado o Plano de Mobilidade Urbana até a data de entrada em vigor desta Lei terão o prazo máximo de sete anos, contado da data de sua entrada em vigor, para elaborá-lo. (BRASIL, 2012).
}

Ainda na mesma lei, "Os Municípios que descumprirem o prazo previsto no § 40 ficarão impedidos de receber recursos federais destinados à mobilidade urbana até que seja elaborado o plano a que refere o caput." (BRASIL, 2012).

Dessa forma, podemos perceber a preocupação do Brasil pela implantação de uma política nacional de mobilidade urbana, a qual prevê prazo e punições para os municípios que não cumprirem o previsto. 
NASCIMENTO, J. C.; PRATES, A. E.; DOURADO, L. F. N.

Mobilidade urbana e transportes não-motorizados: um estudo de caso do uso da bicicleta na cidade de Januária/MG

\section{Material e métodos}

O método de pesquisa utilizado foi pesquisa exploratória, seguido de revisão bibliográfica, que foi feita através de análise documental para identificação das políticas públicas para o uso de bicicletas como modal de transporte e sua aplicação na cidade de Januária, Minas Gerais.

Neste contexto, o levantamento da presente revisão bibliográfica baseia-se nas disposições do Estatuto das Cidades, Lei no 10.257/2001, e a Política Nacional de Mobilidade Urbana, instituída pela Lei no 12.587/2012; além de instrumentos legais no Município; como a Lei Orgânica do Município revisada e aprovada em setembro de 2011; a Lei Complementar ํo 068, de 18 de abril de 2008, a qual instituiu o Plano Diretor Municipal; e o Projeto de Lei Complementar № 004/2016, que se encontra em tramitação até a presente data de averiguação deste estudo, que trata sobre a regulamentação de Estratégia de Mobilidade Urbana do Plano Diretor e institui as diretrizes da Política de Mobilidade Urbana e dá outras providências.

\section{Resultados e discussão}

O município de Januária, situado no Norte de Minas Gerais, tem sua população estimada para 2018 em torno de 67.628 habitantes, de acordo com censo do Instituto Brasileiro de Geografia e Estatística (IBGE) realizado em 2010. É classificado por Amorim Filho, Rigotti e Campos (2007) como um centro emergente1, que é caracterizado pela transição entre pequenas e médias cidades. Assim como outros municípios de mesma hierarquia urbana, Januária teve um aumento significativo da frota de veículos automotores, sobretudo de motocicletas. Entretanto, a população utiliza a bicicleta para os mais variados deslocamentos, como trabalho e escola, já que a cidade não dispõe de sistema público de transporte eficiente.

A cidade conta com apenas um trecho destinado ao tráfego exclusivo de bicicletas, bastante deficitário e a ausência de infraestrutura que atenda tal

\footnotetext{
1 Os centros emergentes apresentam ainda uma economia em estruturação, com discrepância produtiva entre os setores de serviço, indústria e agropecuário, e conexão intensa com o meio rural que os envolvem.
} 
NASCIMENTO, J. C.; PRATES, A. E.; DOURADO, L. F. N.

Mobilidade urbana e transportes não-motorizados: um estudo de caso do uso da bicicleta na cidade de Januária/MG

demanda favorece a falta de segurança viária, o que expõe os ciclistas aos mais variados riscos no trânsito. Trata-se de uma ciclovia, separada fisicamente das vias destinadas ao tráfego motorizado. Tem seu começo no anel rodoviário de Januária, conforme ilustrado na Figura 1, e finaliza na Rua Izabel Carolina de Souza no Distrito de Brejo do Amparo. A ciclovia não dispõe de sinalização eficiente e, conforme ilustrado na Figura 2, não é asfaltada no seu trecho final. Além disso, a ciclovia não faz interligação com a parte central da cidade e nem com os bairros.

Figura 1 - Início da ciclovia no anel rodoviário

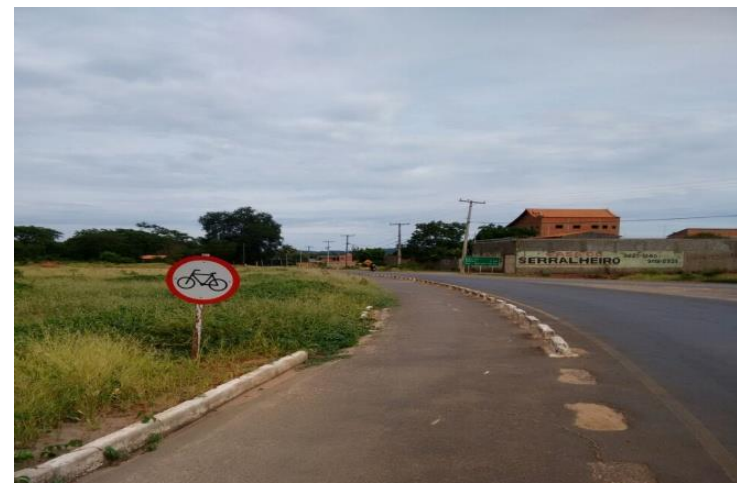

Fonte: (Próprios autores, 2018).

Figura 2 - Final da ciclovia no Distrito de Brejo do Amparo

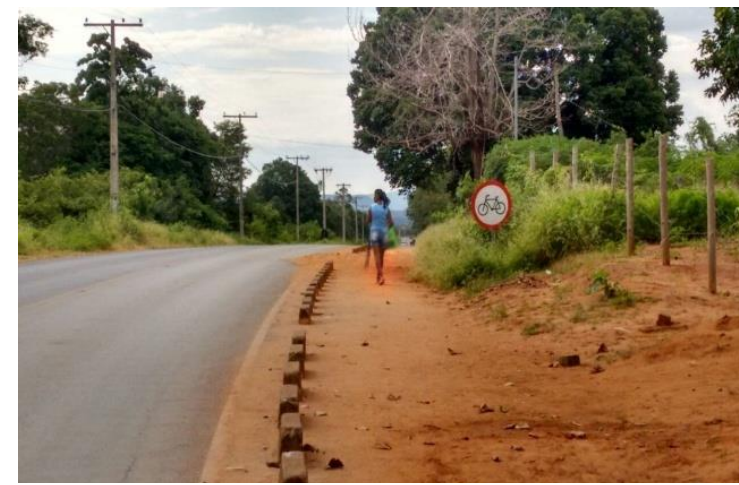

Fonte: (Próprios autores, 2018).

A falta de integração da ciclovia faz com que o deslocamento de ciclistas pela cidade seja deficitário e extremamente perigoso, em razão de os acessos para o centro ser de grande fluxo de veículos automotores, os quais não se atentam para a segurança dos ciclistas, colocando em risco a vida de quem utiliza esse modal.

Além dos problemas para o deslocamento e a falta de ligação por ciclovias ou ciclofaixas, no centro da cidade não há infraestrutura eficiente para a guarda e estacionamento de bicicletas. Como já mencionado, há muitos trabalhadores que 
NASCIMENTO, J. C.; PRATES, A. E.; DOURADO, L. F. N.

Mobilidade urbana e transportes não-motorizados: um estudo de caso do uso da bicicleta na cidade de Januária/MG

fazem uso desse modal não-motorizado para se deslocarem até o centro.

Diante do exposto, buscou-se conhecer e analisar os regimentos e projetos elaborados e implementados pelo poder público local com o objetivo de atender a essa demanda. Tendo como base o que estabelecem o Estatuto das Cidades, Lei $\mathrm{n}^{\circ}$ 10.257/2001, e a Política Nacional de Mobilidade Urbana, instituída pela Lei $\mathrm{n}^{\circ}$ 12.587/2012; averiguou-se que, além da existência de instrumentos legais no Município; como a Lei Orgânica do Município revisada e aprovada em setembro de 2011 e a Lei Complementar $n^{\circ}$ 068, de 18 de abril de 2008, a qual instituiu o Plano Diretor Municipal; encontra-se em tramitação o Projeto de Lei Complementar $N^{\circ}$ 004/2016 que regulamenta a Estratégia de Mobilidade Urbana do Plano Diretor e institui as diretrizes da Política de Mobilidade Urbana e dá outras providências.

A Lei Orgânica do Município em seu Capítulo V, do Título V, estabelece que os dispositivos norteadores para a promoção de um desenvolvimento urbano justo e universal na cidade se dará pela aplicação do Plano Diretor, conforme podemos encontrar no tópico sobre apolítica urbana e rural:

\footnotetext{
Art.166 - A política de desenvolvimento urbano, executada pelo Poder Público municipal, conforme diretrizes gerais fixadas em lei, tem por objetivo ordenar o pleno desenvolvimento das funções sociais da cidade e garantir o bem estar de seus habitantes. $\S 1^{\circ}$ - 0 Plano diretor, aprovado pela Câmara Municipal, é o instrumento básico da política de desenvolvimento e de expansão urbana. $\S 2^{\circ}$ - A propriedade urbana cumpre sua função social quando atender às exigências fundamentais de ordenação da cidade, expressas no plano diretor. $§ 3^{\circ}$ - As desapropriações de imóveis urbanos serão feitas com prévia e justa indenização em dinheiro (JANUÁRIA, 2011, p. 49).
}

Seguindo as normas estabelecidas pelo Estatuto das Cidades, o Plano Diretor do Município de Januária contempla a necessidade de promoção de uma cidade sustentável e acessível a todos os seus cidadãos. Assim sendo, conforme os princípios do plano diretor, o foco é “I - promover diretrizes, objetivos, estratégias, metas e ações para implementação e controle de políticas públicas de desenvolvimento urbano, rural, econômico, social, educativo, ambiental, administrativo e de integração do Município e Região.” (JANUÁRIA, 2008, p. 01).

O Plano Diretor ainda têm como objetivos os seguintes princípios norteadores:

II - promover o desenvolvimento sustentável do Município; III - definir e nortear a função social da cidade e garantir o cumprimento da função 
NASCIMENTO, J. C.; PRATES, A. E.; DOURADO, L. F. N.

Mobilidade urbana e transportes não-motorizados: um estudo de caso do uso da bicicleta na cidade de Januária/MG

social da propriedade de áreas e zonas do Município; IV - garantir o direito à cidade, compreendendo o direito a terra urbana, a infra-estrutura urbana, ao transporte público, aos serviços públicos com qualidade, ao trabalho e ao lazer, visando o bem estar dos cidadãos; $V$ - garantir a gestão democrática e participativa nos processos de decisão, planejamento, gestão, implementação e controle do desenvolvimento urbano, sóciocultural e educacional da cidade (...) (JANUÁRIA, 2008, p. 01).

$\mathrm{Na}$ medida em que as cidades crescem, cresce também a necessidade de construção de mobilidade sustentável, com práticas que levem em consideração a questão ambiental, econômica e social, que busque um desenvolvimento ambientalmente equilibrado, economicamente viável e socialmente justo (CAMPOS, 2006). No que tange à mobilidade urbana sustentável, ressalta-se no Art. $8^{\circ}$ os objetivos do Plano Diretor:

I - promover a inclusão e a redução das desigualdades sociais, garantindo à população o acesso a bens, serviços e políticas sociais; (...)IV - definir os instrumentos da Política Urbana; V - definir o planejamento viário municipal e sua hierarquia; (...)IX - promover a acessibilidade universal em vias públicas, no transporte coletivo e edifícios de uso público, adotando, para isso, integralmente a Norma Técnica NBR 9050, da Associação Brasileira de Normas Técnicas - ABNT de 1994; X - priorizar o transporte coletivo público de passageiros; XI - incentivar a implantação de ciclovias nas principais avenidas da cidade e em áreas verdes públicas e de fundo de vale, visando o lazer e o transporte (...) (JANUÁRIA, 2008, p. 02).

Ainda, no artigo $8^{\circ}$, encontramos uma normativa que aponta para campanhas educativas para o trânsito e diretrizes para políticas urbana e rural no município e região.

XII - promover campanhas educativas de humanização no trânsito; (...)XXVIII - criar mecanismos que garantam a participação da população nos processos de decisão, planejamento, gestão, implementação e controle do desenvolvimento urbano; XXIX - determinar diretrizes e ações para a implantação de políticas de desenvolvimento urbano, rural, econômico e social, visando a integração do Município na Região; (...) (JANUÁRIA, 2008, p. 02).

Em continuidade, ao abordar sobre o Sistema de Trânsito e Transporte do município, em seu Capítulo VII, o referido plano restringe o conceito de mobilidade urbana sustentável, como está apontado no artigo 73:

I - Respeitar o direito fundamental do cidadão ao transporte; II - garantir a circulação das pessoas e dos bens necessários ao funcionamento do sistema social e produtivo; III - promover a melhoria dos sistemas de circulação; IV - priorizar a circulação dos pedestres em relação aos veículos e dos veículos coletivos em relação aos particulares; (...) (JANUÁRIA, 2008, p. 16). 
Como já apresentado na estruturação deste artigo, sabe-se que a Política Nacional de Mobilidade Urbana prioriza os meios não-motorizados sobre os motorizados, e o transporte público coletivo sobre o individual motorizado, cabendo aqui uma revisão. A falha pode ser justificada devido à revisão e aprovação do Plano Diretor ter sido anterior à publicação da Lei 12.587/2012.

No que tange ao sistema cicloviário, este só recebe destaque no plano no inciso XI do Artigo $8^{\circ}$, já citado neste artigo, ao destacar a importância de implantação de ciclovias nas principais avenidas da cidade. Aparece, também, na Seção Ildo Art. 34 como parte importante da infraestrutura física das vias, segundo definição:

Art. 34. Constituem diretrizes específicas de uso do solo para a organização físico-territorial da Área Urbana do Município: (...)V - Ciclovias: são aquelas destinadas ao uso de bicicletas, separadas fisicamente das vias destinadas ao tráfego motorizado e devem ser implantadas nas Vias marginais aos córregos e, Vias arteriais e Vias coletoras, de acordo com necessidades específicas (...) (JANUÁRIA, 2008, p. 10).

Conforme analisado no Plano Diretor, a rede cicloviária ainda não tem seu destaque e incentivo como um importante instrumento para a variação dos modais de transporte da cidade de maneira segura, econômica e sustentável, uma vez que ainda se consolida como meio de locomoção bastante utilizado pelos januarenses. É um modal adequado para a interligação entre bairros e locais de uso para lazer e serviços públicos, bem como áreas de trabalho, estudo e outras atividades comuns.

Entretanto, a definição estratégica e eficiente do uso da bicicleta no sistema viário, de maneira segura para os ciclistas, deve ser definida no Plano de Mobilidade Urbana como instrumento regulador da política de desenvolvimento urbano, que objetiva a integração entre os diferentes modos de transporte e a melhoria da acessibilidade e mobilidade das pessoas e cargas no território do Município, a partir das diretrizes do Plano Diretor Municipal. Esse norte está registrado no Projeto de Lei Complementar $N^{\circ}$ 004/2016, que regulamenta a estratégia de Mobilidade Urbana do Plano Diretor e institui as diretrizes da Política de Mobilidade Urbana do município.

Em observância ao transporte não-motorizado por bicicletas, merece destaque o Art. 12 do Projeto de Lei, que ressalta sobre a composição de 
NASCIMENTO, J. C.; PRATES, A. E.; DOURADO, L. F. N.

Mobilidade urbana e transportes não-motorizados: um estudo de caso do uso da bicicleta na cidade de Januária/MG

infraestrutura para destinações de mobilidade urbana em consonância com o Plano diretor, e o Art. 38 que estabelece o diagnóstico de mobilidade a ser realizado para que os objetivos da Política de Mobilidade Urbana sejam contemplados.

Art. 38 - Para o alcance dos objetivos da Política de Mobilidade Urbana, a Secretaria Municipal de Planejamento e Controle Orçamentário realizará diagnóstico que permita identificar aspectos referentes ao transporte e ao trânsito a serem trabalhados, de modo a possibilitar a elaboração de projetos voltados para a Mobilidade. $\S 1^{\circ}$ - 0 Diagnóstico de Mobilidade deverá prever: I - áreas de acesso restrito ou controlado; II - espaços para instalação de estacionamentos dissuasórios; III - medidas que favoreçam a circulação de pedestres e ciclistas; IV - medidas que possibilitem minimizar os conflitos intermodais (JANUÁRIA, 2016, p. 37-39).

Ainda em consonância ao artigo 38, encontramos abordagens sobre projeto paisagístico, pavimentação de vias e ciclofaixas como é apresentado logo abaixo:

V - delimitação de áreas prioritárias a serem tratadas por meio de: a) projeto paisagístico; b) revitalização da infraestrutura do sistema viário; c) pavimentação de vias; d) construção ou manutenção de passeios; e) sinalização viária; f) implantação de ciclovias ou ciclofaixas; g) implantação de terminais, estações de embarque/desembarque e abrigos para pontos de parada; $\mathrm{VI}$ - formas de financiamento e parcerias a serem firmadas. (JANUÁRIA, 2016, p. 37-39).

O artigo 37 nos mostra a importância de o município trabalhar a infraestrutura para os fins de mobilidade urbana e com ciclovias.

\begin{abstract}
Integrado ao Plano Diretor do Município que é instrumento dinâmico voltado para a modernização da gestão pública e para fins do estabelecimento da organização físico territorial do Município de Januária, esta Lei considera infraestrutura para os fins de mobilidade urbana: I - vias e demais logradouros públicos, inclusive ciclovias e outros; II estacionamentos; III - terminais e demais conexões; IV - pontos para embarque e desembarque de passageiros e cargas; $V$ - sinalização viária e de trânsito; VI - equipamentos e instalações. (JANUÁRIA, 2016, p. 37-39).
\end{abstract}

No que diz respeito à mobilidade, acessibilidade e segurança para os ciclistas, o Art. 12 do Projeto de Lei, que ressalta sobre os objetivos gerais do Plano de Mobilidade Urbana de Januária, garante:

I - Promover: a) a inclusão social; b) o acesso aos serviços básicos; c) o acesso aos equipamentos sociais; d) a melhoria nas condições urbanas da população dos serviços básicos; e) a acessibilidade e à mobilidade; f) o desenvolvimento sustentável; g) o estímulo ao uso de modos não motorizados; h) a consolidação da gestão democrática da Cidade. II Assegurar: a) a construção contínua do aprimoramento da mobilidade urbana; (JANUÁRIA, 2016, p. 15-16). 
Ainda no artigo 12, encontramos a pauta sobre serviços, equipamentos e instalações de mobilidade e segurança no transito.

b) a redução dos custos nas áreas ambiental, social e econômica com os deslocamentos de pessoas e cargas nas cidades; c) a melhoria permanente dos serviços, equipamentos e instalações relacionados à mobilidade;d) a segurança no trânsito. (JANUÁRIA, 2016, p. 15-16).

Apesar de ainda não ter sido aprovado, o Projeto de Lei Complementar $\mathrm{N}^{\circ}$ 004/2016 se apresenta como importante instrumento da política de desenvolvimento urbano do município. Entretanto, há necessidade de ser discutido e aprovado com a participação de todos os setores da sociedade, complementado com as seguintes diretrizes, para que favoreçam aos ciclistas: elaboração com a participação popular de um Plano Cicloviário Municipal, de forma que atenda de maneira sustentável as necessidades dos ciclistas e beneficie a ligação interbairros e destes com os principais pontos de oferta dos serviços públicos e equipamentos urbanos de lazer, esporte, estudo, entre outros; construção de rede cicloviária integrada, interligando os bairros ao centro urbano e espaços de serviços públicos e lazer da cidade; implementação de bicicletários públicos nas regiões de maior circulação da cidade, para guarda e estacionamento das bicicletas utilizadas pela população.

\section{Conclusões}

A Mobilidade Urbana, nas últimas décadas, tornou-se uma razão de preocupação na formulação e na implementação de políticas públicas de desenvolvimento urbano, tendo como propósito a necessidade de priorização dos transportes não motorizados e transportes públicos coletivos.

No entanto, a elaboração de medidas que solucionem sustentavelmente as condições de deslocamento da população nas cidades, enfrentam desafios a serem resolvidos, sendo que, para isso, faz-se necessária a reconstrução de valores atribuídos às políticas públicas, que necessitam ser formuladas de maneira democrática, com a participação de toda sociedade, com o objetivo conjunto de encontrar soluções efetivas que permitam a melhoria na qualidade de vida da 
NASCIMENTO, J. C.; PRATES, A. E.; DOURADO, L. F. N.

Mobilidade urbana e transportes não-motorizados: um estudo de caso do uso da bicicleta na cidade de Januária/MG

população atual e das gerações futuras.

O Município de Januária/MG possui, apesar dos seus problemas e desafios, as condições para se tornar uma cidade ciclável e com mobilidade urbana eficiente. Deve-se favorecer uma política de desenvolvimento urbano eficaz, com o intuito de promover um meio urbano mais seguro, saudável, equânime e universal para toda a população.

A utilização de bicicletas como modal constitui-se uma realidade muito comum e seu nível de uso varia, geralmente, conforme a realidade socioeconômica da população. Fazendo parte de uma realidade de cidades de pequeno e médio porte, como o caso de Januária, e sendo não apenas um veículo de lazer, mas um importante meio de transporte e, por vezes, único para grande parcela da população de baixa renda. É fundamental que a forma como esse modal é tratado pelo poder público seja devidamente modificada.

Dessa forma, é necessário que as políticas públicas sejam devidamente implementadas de maneira a atender o uso de bicicletas, garantindo mobilidade, acessibilidade e segurança para os ciclistas, tornando a cidade plenamente acessível a todos os seus cidadãos, pois a bicicleta faz parte da rotina da população, principalmente a de baixa renda, que usa bicicleta para se locomover, e a infraestrutura precária e/ou ausente torna-se uma fator que dificulta a implementação de política de mobilidade, dos meios de transportes não motorizados.

\section{Referências}

AMORIM FILHO, O. B.; RIGOTTI, J. I. R; J. CAMPOS. Os níveis hierárquicos das cidades médias de Minas Gerais. R. RA'E GA, Curitiba, n. 13, p. 7-18, 2007. Editora UFPR.

BRASIL. Ministério das Cidades. Programa Brasileiro de Mobilidade por Bicicleta. Coleção Bicicleta Brasil - Caderno 1. Brasília-DF, 2007. 235 p.

BRASIL. Lei No 10.257/2001 - Estatuto das Cidades. Disponível em: <http://www.planalto.gov.br/ccivil_03/leis/LEIS_2001/L10257.htm>. Acesso em: 20/01/18.

BRASIL. Lei No 12.587/2012 - Política Nacional de Mobilidade Urbana. Disponível em: <http://www.planalto.gov.br/ccivil_03/_ato2011-2014/2012/lei//12587.htm>. Acesso em: 20/01/2018. 
NASCIMENTO, J. C.; PRATES, A. E.; DOURADO, L. F. N.

Mobilidade urbana e transportes não-motorizados: um estudo de caso do uso da bicicleta na cidade de Januária/MG

BRASIL. Ministério das Cidades. Instituto Brasileiro de Administração Municipal. Mobilidade e política urbana: subsídios para uma gestão integrada. Rio de Janeiro, 2005, 52 p.

IBGE - Instituto Brasileiro de Geografia e Estatística. Cidades - Minas Gerais Januária. Disponível em: <https://www.ibge.gov.br/geocienciasnovoportal/organizacao-do-territorio/estrutura-territorial/15761-areas-dosmunicipios.html? $\mathrm{tt}=$ destaques $>$. Acesso em: 20/01/2018.

JANUÁRIA. Câmara Municipal de Januária. Lei Orgânica do Município de Januária. Januária-MG, 2011. $66 \quad$ p.Disponível em: <http://camarajanuaria.mg.gov.br/site/images/lei_organica/lei_organica_municipi o_januaria.pdf>. Acesso em: 21/01/2018.

JANUÁRIA. Câmara Municipal de Januária. Lei Complementar N 068/2008 - Plano Diretor do Município de Januária. Januária-MG, 2008. 42 p. Disponível em: <http://camarajanuaria.mg.gov.br/site/index.php/legislacao/leicomplementar/361--225/file>. Acesso em: 21/01/2018.

JANUÁRIA. Câmara Municipal de Januária. Projeto de Lei Complementar 004/2016 - Regulamenta a Estratégia de Mobilidade Urbana do Plano Diretor. Januária-MG, $2016 . \quad 55 \quad$ p. $\quad$ Disponível em: <http://camarajanuaria.mg.gov.br/site/images/projetos/projeto_lei_comp_004_20 16_mobilidade_urbana.pdf>. Acesso em: 21/01/2018.

SILVA, M. S. S. O uso de bicicletas como modal para a mobilidade urbana no município de Castanhal, estado do Pará. Universidade do Sul de Santa Catarina, Santa Catarina, 2017.

Disponível em:<https://riuni.unisul.br/bitstream/handle/12345/2386/Artigo\%20Cient\%C3\%ADf ico\%20-\%20M\%C3\%A1rio\%20Silva\%20-

\%200\%20Uso\%20de\%20Bicicletas\%20como\%20modal....pdf?sequence=1\&isAllowed=y >. Acesso em: 27/12/2017.

SIQUEIRA, G. D. P.; LIMA, J. P. A contribuição das políticas públicas de mobilidade urbana para o desenvolvimento sustentável das cidades. Universidade Federal de Itajubá, Itajubá, 2015. Disponível em: <http://www.rio2015.esocite.org/resources/anais/5/1440766741_ARQUIVO_Artigop araoTECSOC.pdf>. Acesso em: 20/01/2018.

XAVIER, G. N. A. O cicloativismo no Brasil e a produção da lei de política nacional de mobilidade urbana. Revista Eletrônica dos Pós-Graduandos em Sociologia Política da UFSC. Vol. 3 n. 2 (2). Santa Catarina. 2007. 122-145 p. 